Zbornik Instituta za kriminološka

i sociološka istraživanja

2021 / Vol. XL / 2-3 / 77-89

Pregledni naučni rad

Primljeno: 8. 11. 2021. godine

Prihvaćeno: 23. 11. 2021. godine

DOI: $10.47152 /$ ziksi202123025

UDK: 343.9:811.214.58'276.4

\title{
KRIMINALNI ARGO (ŠATROVAČKI) I POZAJMLJENICE IZ ROMSKOG JEZIKA*
}

\author{
Andrej Kubiček*
}

\begin{abstract}
Polazeći od pretpostavke da leksika jednog jezika - standardnog ili nekog drugog njegovog oblika - svedoči o temeljnim društvenim procesima, članak se bavi nastankom i razvojem takozvanog šatrovačkog govora. Da bi se postigao ovaj cilj, neophodno je prvo uvesti pojmovnu razliku između srodnih fenomena: žargona, slenga $i$ argoa (šatrovačkog, kanta ili kriptolekta). Iako se ovi jezički varijeteti često smatraju spontano nastalim i efemernim, u radu će biti pokazano da se često radi o trajnim jezičkim pojavama koje karakterišu kriminalne i marginalizovane subkulture. U posebnom fokusu će biti nastanak nove leksike pozajmljivanjem iz romskog jezika. Članak istražuje genezu i funkciju ovih govornih praksi, ističući sličnosti koje postoje u više evropskih jezika i koje svedoče o sličnim društvenim procesima. Konačno, rad ima cilj i da ukaže na poroznost simboličkih granica između marginalizovanih $i$ etabliranih načina izražavanja kroz njihovo međusobno prožimanje.
\end{abstract}

KLJUČNE REČI: šatrovački / argo / žargon / romski jezik / pozajmljenice.

\footnotetext{
* Ovaj rad nastao je kao rezultat istraživačkog angažovanja prema Planu i programu rada Instituta za kriminološka i sociološka istraživanja za 2021. godinu.

* Istraživač saradnik na Institutu za kriminološka i sociološka istraživanja u Beogradu. Email: andrejkubichek@iksi.ac.rs
} 


\author{
Zbornik IKSI, 2-3/2021 - A. Kubiček \\ „Kriminalni argo (šatrovački) i pozajmljenice iz romskog jezika”, (str. 77-89)
}

\title{
1. UVOD
}

Romski jezik, iako ga je moguće čuti doslovno čitav milenijum u Evropi, dugo je predstavljao misteriju. Spoznaja da se radi o jeziku koji izvorno potiče iz južne Azije javila se krajem 18. veka (Đurić, 2021), ali ona isprva nije doprinela objektivnom razumevanju njegovih govornika. Naprotiv, esencijalizacija indijskog porekla Roma često je dovodila do opravdavanja njihove marginalizacije, kao i dalje mistifikacije navodnih razloga za takve prakse.

Za romski se katkad slikovito tvrdi da predstavlja „najznačajniju istorijsku knjigu” o pripadnicima ovog naroda, usled malog broja pisanih izvora o njihovoj prošlosti. Istraživanje različitih leksičkih i morfoloških slojeva romskog jezika opravdava ovo zapažanje. Njegova osnova nedvosmisleno ukazuje na indo-iransko jezičko i indijsko geografsko poreklo. Međutim, uticaji govornika persijskog jezika (ne nužno i Persijanaca) i jermenskog ukazuju na migracije predaka današnjih Roma kroz današnji Avganistan, Iran, Kavkaz i Anatoliju. Još snažniji uticaj grčkog, slovenskih i balkanskih romanskih jezika svedoče o trajnom životu Roma na prostoru Jugoistočne Evrope. Lingvisti s pravom romski uvršćuju u balkanski sprachbund (Schrammel, Halwachs, 2005), zbog čega je on istovremeno i evropski jezik. Ovome treba dodati i da je romski jedan od nekoliko primera jezika koji su se razvijali van okvira nacionalne države ${ }^{1}$.

Za razliku od Roma, koji su istorijski vladali jezicima sredina u kojima su živeli, pripadnici okolnih naroda su retko znali - a i dalje retko znaju - romski (Kubiček, 2018). Upliv leksike romskog u evropske jezike ipak postoji, iako u znatno manjoj meri nego što je ovaj proces tekao u suprotnom smeru. Potraga za romizmima u književnom jeziku i drugim prestižnim varijetetima gotovo da je uzaludna, za razliku od govornih oblika jezika, a naročito onih kojima se često posvećuje manje pažnje, ili koji su stigmatizovani zajedno sa svojim govornicima.

Istraživanje jezika iz sociološke perspektive uključuje razumevanje različitih ljudskih svetova, identiteta i uloga. Komunikacija je izrazito složena, pa je za njeno tumačenje potrebno razmotriti sve ove slojeve značenja. Pojedinac, govornik, povezuje ono što je naučio u jednom kontekstu s načinima na koji se njegovo delovanje generiše u drugačijim kontekstima. To znači da otkrivanje značenja individualnih govornih praksi zahteva smeštanje u mnogo širi kontekst delovanja: od formalnih institucija, do spontanih procesa (Leburić, Šuljug, 2008: 143-144).

\footnotetext{
${ }^{1} \mathrm{U}$ čemu nije usamljen u konteksu jezika Balkanskog poluostrva i Srbije, na kome su istorijski bili prisutni i jidiš, ladino (jezici Jevreja) i aromunski (jezik Cincara).
} 


\section{SOCIOLINGVISTIČKI ASPEKTI ŽARGONA, SLENGA I ARGOA}

Jedno od osnovnih polazišta sociolingvistike jeste da je jezik u društvenoj upotrebi uvek višestruko diferenciran. Da bi se sve te razlike u govoru konceptualno obuhvatile, obično se koristi pojam varïjetet (Filipović, 2009). Književni, klasični ili liturgijski jezici su, dakle, jednako varijeteti kao što su to i regionalni govori, jezik mladih u nekom gradu ili tehnički rečnik lekara ili pravnika. Jedan od razloga uvođenja varijeteta kao vrednosno neutralnog pojma je upravo da se izbegne normativistička stigmatizacija govornika „nestandardnih varijeteta” kao manje prestižnih, čime se jezička raznovsnost prikazuje kao preslikana hijerarhijska struktura društvene moći (Petrović, 2015).

Osnove za raslojavanje jezika su raznovrsne, a mogu se grupisati u sledeće osnovne tipove: (1) funkcionalna, (2) socijalna, (3) individualna i (4) teritorijalna (Radovanović, 1979: 63). Za razumevanje žargona, ključna je druga, društvena osnova, budući da su žargoni možda i najpoznatiji sociolekti, kako u akademskoj literaturi, tako i u svakodnevnom govoru. Upravo zato se javljaju i poteškoće u nastojanju da se ovaj pojam precizno odredi, kako to Dragoslav Andrić primećuje „sam pojam žargona živo oscilira od jezika struke do jezika ulice” (Andrić 1976: 7). Ranko Bugarski ispravno dodaje da širok raspon između ova dva pola definisanja (struke i „ulice”) ukazuje na to da žargon zapravo podrazumeva dve ne samo različite, nego i suprotne pojave. Žargon kao način govora (lekara, pravnika, političara i administracije) je izrazito šabloniziran i repetitivan, nasuprot žargonu kao vrsti jezika (omladine, „ulice”, pa i kriminala), koji je spontan i kreativan (Bugarski, 2005: 211).

Sleng uvek pripada drugom načinu definisanja žargona (Bugarski, 2005: 211-212). Kao što je često slučaj i kod definisanja ovog pojma autori predlažu određivanje nekoliko bitnih elemenata: (1) nizak prestiž govorne situacije, (2) govornikovo poznavanje ovog manje prestižnog govora, (3) tabuiziranost slenga u prestižnim govornim situacijama i (4) leksiku slenga koja ima sinonime u konvencionalnom jeziku, ali njegova upotreba služi da bi se umanjila napetost kod govornika i da bi se komunikacija pojednostavila (Eble, 1996: 11-12). Upotreba slenga pojačava zajedništvo između govornika, stoga ima značajnu ulogu u neformalnim grupama koje njegovom upotrebom afirmišu osećaj zajedništva. Sleng se smatra u suštini efemernim i sklonom promenama, jer određene reči vrlo brzo izlaze iz upotrebe, ili postaju odlika generacijskog žargona, koji vremenom postaje antikvaran i na kraju zaboravljen. Ipak, postoje primeri leksike koja može da ima i trajno prisustvo u jeziku, ali koja nikada ne postaje deo književnog varijeteta, te uvek nosi i nizak prestiž (engleski izraz bones za kockice za igru postoji od 14. veka do danas) (Eble, 1996: 16). Treba napomenuti i da sleng, osim navedenih osobina koje se pozitivno ocenjuju, (poetičnost, spontanost, maštovitost, koloritnost) često biva i stigmatizovan kao traljav, vulgaran, ružan i trivijalan način izražavanja (Coleman, 2012: 1). 


\author{
Zbornik IKSI, 2-3/2021 - A. Kubiček \\ „Kriminalni argo (šatrovački) i pozajmljenice iz romskog jezika”, (str. 77-89)
}

Pojedini autori izdvajaju argo ili kant kao posebne vrste slenga - kriptolekte (tajne govore). Prema ovom shvatanju, dok sleng može da bude vezan i za nekriminalizovane grupe (mornare, zidare), ovi varijeteti se isključivo govore unutar grupa koje su na margini ili van zakona (narkomani, kockari, prostitutke, kriminalci) (Eble, 1996: 21). Počev od XVI veka i kroz čitav XVII vek u Engleskoj je postojalo široko rašireno verovanje o postojanju „tajnog govora” lopova, vagabunda i prosjaka (eng. Thieves' cant). Danas se sa sigurnošću zna da je ovaj ,jezik” više plod popularne literature, pamfleta i pozorišnih komada onog vremena nego što je istorijska i društvena činjenica (Kinney, 1990). Ipak, ova predstava je dugo ostala ukorenjena sa čestim povezivanjem ovog tobožnjeg govora sa jezikom „Egipćana” (predaka današnjih Roma) ${ }^{2}$.

U savremenom kontekstu srpskog ili hrvatskog, šatrovačkim se naziva pojava izvrtanja slogova3, ali i glasova unutar sloga, nalik francuskom verlan-u (Ćosić, 2004: 14). Pavle Ćosić navodi da se ova (uslovno nazvana) metateza u srpskom ili hrvatskom javlja početkom i sredinom XX veka u velikim urbanim centrima (Beogradu, Sarajevu i Zagrebu), i da se proširila i na manje gradove u Srbiji, Bosni i delovima Hrvatske (Slavoniji, ali ne i u Dalmaciji). Sam izraz šatrovački, međutim, znatno je stariji i zapravo predstavlja izvoran domaći naziv za argo ili kant, a etimološki ga neki autori povezuju sa precima Roma. Tako Pavle Ćosić tvdi da je šatrovački nastao „Od ciganskog šatra, što je dakle u početku označavalo ciganske reči koje su ušle u srpskohrvatski” (Ćosić, 2004: 14). Ipak, postoji i drugo tumačenje, koje vezu srpskog ili hrvatskog i šatrovačkog vidi više topički nego etnički: vašari i sajmovi su, naime, oduvek bili mesta okupljanja džeparoša, prevaranata i drugih marginalizovanih osoba (Marković, 2021: 148). Ovo drugo tumačenje je vrlo interesantno, budući da ima gotovo preslikanu paralelu u engleskom terminu Grafter's talk - „govor tezgaroša”. U prilog drugom tumačenju ide i podatak da se već u prvom broju Policijskog glasnika, u odeljku naslovljenom „Kockarski egavački jezik”4, navodi da „šatrovac” znači lopov, a „gorak šatrovac” - „ajduk” (Policijski glasnik, 1897: 7). Pregled ostalih brojeva ovog lista opovrgava Ćosićevo povezivanje kriminalnog slenga $i \mathrm{i}$ „cigana” jer se u njima javlja samo nekoliko reči romskog porekla, dok su ostale nastale alteracijama reči iz matičnog jezika, odnosno srpskog.

\title{
3. KRIMINALNI SLENG ILI ARGO
}

O postojanju slenga karakterističnog za (bivše) osuđenike i kriminalce pisao je još Ćezare Lombrozo, delom i na osnovu ranijih uverenja o tajnom „jeziku lopova”:

\footnotetext{
${ }^{2}$ Izvesni Valter Hajndes je zabeležio određen leksički korpus romskih reči 1616. godine („reči kao one koje krivotvoreni Egipćani koriste među sobom”) dok je bio u tamnici (!) u Vinčesteru (Bakker, 2002: 75).

3 Poseban oblik šatrovačkog podrazumeva gubljenje prvog sloga, na koji način su nastale neki od poznatih izraza koje se koriste u kriminalnom slengu, poput vala, od provala (stana ili kuće).

4 „Nije s gorega da polic. činovnici znaju i ovaj kockarski jezik jer im u prilikama može koristiti, $\mathrm{s}$ toga i ovu rubliku otvaramo". Ova rublika je zaista izlazila, iako ne u svakom broju. Takođe, zanimljivo je da je i izraz „kockar” korišćen kao sinonim za lopova i kriminalce uopšte.
} 
„Slang. Ovo je specifičan žargon koji kriminalci koriste kada razgovaraju među sobom. Sintaksa i gramatička konstrukcija jezika ostaju nepromenjene, ali su značenja reči izmenjena, mnoga na način kao što je to u primitivnim jezicima, to jest, predmet dobija ime po nekom svom atributu" (Lombroso, 1911a: 42). Ovo Lombrozovo zapažanje, bez etiketiranja jezičkih pravila kao primitivnih, moguće je zapaziti i kod nas. Primer za to bi bio izraz mečka za kasu ili sef, čime se želi istaći gabarit iste/istog; žutara za zlatarsku radnju; štemovati - tući nekoga itd. Drugi način formiranja nove leksike u osuđeničkom/kriminalnom slengu Lombrozo vidi u onomatopejama (Lombroso, 1911a) ( primeri kod nas: čuka „sat”; koknuti, zviznuti, zveknuti „udariti”). Citirani autor se bavi ovom temom i na drugim mestima u svom radu, tvrdeći da postoje kriminalci koji ne znaju ni jedan drugi jezik osim „slenga” (Lombroso, 1911b: 333), ali i da se susretao sa zatvorenicima koji niti umeju da govore slengom, niti su imalo cinični (Lombroso, 1911b: 438).

Što se tiče funkcije ovakvog jezika, Lombrozo je tumači višestruko. Sleng sa jedne strane služi da bi se zavarala policija, ali sa druge i da bi se privukla pažnja običnih ljudi ili čak da bi se i pisale pesme. Ipak, već tada Lombrozo postavlja pitanje: zbog čega kriminalci koriste sleng i među sobom, kada ne postoji rizik da će ih iko čuti? (Lombroso, 1911a: 43). On svakako služi za izražavanje zajedničkog identiteta, ali treba imati u vidu da ne postoji samo jedan, jedinstven sleng. Neki slengovi su karakteristični za zajednice govornika na nivou cele države, dok su drugi vezani za uske, lokalne grupe (Eble, 1996: 19)

U novijoj domaćoj literaturi prilazi se sa oprezom praktičnoj (konspirativnoj) funkciji slenga osuđenika. Razlog za to je jednostavan - zatvorsko osoblje i policajci vrlo brzo otkriju značenje novih reči i izraza (Nikolić, 2009: 244). Zbog toga upotreba slenga među zatvorenicima pre ima funkciju prevladavanja zatvorskih deprivacija (Ilijić, 2014: 140; Batrićević, Kubiček, 2020: 15-16) kroz društvene funkcije slenga o kojima je već bilo reči ranije u radu (spontanost u komunikaciji i afirmaciju identiteta kroz odbacivanje spoljnih simboličkih okvira, konkretno jezičkih konvencija).

Što se tiče istorije kriminalanog slenga na prostorima bivše Jugoslavije (odnosno na govornom području srpskog ili hrvatskog jezika) 5 , tragovi o njegovom postojanju su stari koliko i sistematska filološka istraživanja. Još je Vuk Karadžić početkom 19. veka zabeležio postojanje gegavačkog govora u Sremu i Slavoniji, tajnog govora gegavaca (slepih prosjaka, kako pravih, tako i onih drugih) (Sikimić, 1992: 276). Krajem 19. veka (1897. godine) u Policijskom glasniku zabeleženo je nekoliko reči

\footnotetext{
${ }^{5}$ Namerno se izbegava zadržavanje na teritoriji Republike Srbije, jer kao što je bilo reči, kriminalni sleng je u najvećoj meri zajednički na prostoru bivše Jugoslavije, odnosno srpskom ili hrvatskom jeziku u celini. Upravo Malinarov spis jasno ukazuje da je ovo bio slučaj i pre nastanka Jugoslavije, odnosno da je zajednički srpski i hrvatski sleng postojao još u Austro-Ugarskoj. Uostalom, bilo bi apsurno tvrditi da je neka kasnija jezička politika mogla da normira zajednički govor zatvorenika i kriminalaca. Već letimičan pogled na rečnike savremenog zagrebačkog žargona sto godina kasnije jasno pokazuje da je on i dalje gotovo identičan onom koji se koristi u Beogradu.
} 


\author{
Zbornik IKSI, 2-3/2021 - A. Kubiček \\ „Kriminalni argo (̌̌atrovački) i pozajmljenice iz romskog jezika”, (str. 77-89)
}

beogradskog kriminalnog slenga, od kojih se neke i danas koriste6. Dušan Alimpić je 1924. godine objavio trodelni Policiski rečnik, a 1928. Živko D. Petrović izdaje Jezik naših šatrovaca. Deceniju kasnije (1935. godine), u Zagrebu pojavio se Riječnik jugoslavenskih šatrovaca Munira Šahinpašića Ekremova, kao deo biblioteke Savremena policija. Ipak, za bolje razumevanje ove teme naročito je značajan napis Zločinački ili šatrovački jezik koji je sastavio pravnik Mato Malinar 1912. godine u Mjesečniku Pravničkoga družtva u Zagrebu, ali koji se bavi mestom od suštinskog značaja za istoriju kriminala u Republici Srbiji: Sremskoj Mitrovici (Marković, 2021: 146).

\title{
4. VARIJETETI JEZIKA U DODIRU: POZAJMLJENICE
}

Osim navedenih načina geneze novih reči (rimovanje, metateza, skraćivanje, sažimanje, analogije...), čest izvor inovacija u leksici predstavljaju i pozajmljenice. Prihvatanje pozajmljenica je često društveno uslovljeno, posebno ako se uzme u obzir nimalo slučajna određenost različitih domena u kojima se reči iz određenog jezika prihvataju7.

Izvestan broj reči kriminalnog žargona, odnosno slenga, takođe potiču iz stranih jezika. Ovaj važan aspekt je takođe primetio Ćezare Lombrozo, tvrdeći da $\mathrm{u}$ engleskom i nemačkom kriminalnom slengu postoji veliki broj ,jevrejskih reči” (misleći na reči iz jidiša), jer su upravo Jevreji bili glavni kupci kradenih stvari, zbog čega su ih lopovi smatrali za svoje „gospodare i predvodnike” (Lombroso, 1911b: 39). U engleskoj literaturi moguće je naći izraz Grafter's slang („tezgarski” sleng) kojim govore oni koji rade na pijacama i vašarima, na primer gatare i nadrilekari, a koji je nastao mešanjem jidiša, romskog i rimovanjem reči8 (Partridge, 2006: 13). Drugi vid engleskog slenga koji sadrži romske reči je Mumper's talk (Partridge, 2006: 14) prosjački govor.

U srpskom ili hrvatskom takođe susrećemo reči u vezi sa kriminalom koje potiču iz jezika zemalja u kojima su kriminalci sa naših prostora bili aktivni: italijanskog (murija, ćuza, tropa) i nemačkog (bajbok, štajga, šljaga, druker-drukati, drot, trufa, kibicovati). Sa druge strane, savremeni sleng narkomana i kriminalnih krugova u vezi sa drogom je uglavnom preuzet iz engleskog jezika (dop, hors, spid, džanki, trip...). Prisutne su i reči preuzete iz susednih ili manjinskih jezika, pre svega iz

\footnotetext{
${ }^{6}$ Gljati (giljati) u značenju „ići” (nota bene, radi se po svoj prilici o glagolu romskog porekla, gelo „ide” (Krasnići, 2012: 155)); baštati „udariti”; klinac „dete”; gotiviti „dopadati se”; mardelj „zatvor” (takođe pozajmljenica iz romskog, koja je stigla posredstvom rumunskog mardeală, tući. Naime, glagol mardo na romskom ima više značenja: tući, tucati, kucati, lupati (Krasnići, 2012: 257)) (Sikimić, 1992: 276-277).

7 Srpski jezik pruža ilustrativne i zanimljive primere. Tako su mnoge reči iz religijskog domena pozajmljene iz grčkog jezika (nafora, ikona, ikonostas, mitra...) dok su iz osmanskog turskog prihvaćene mnoge reči za pokućstvo (jorgan, jastuk, krevet, čaša, kašika, ćasa...) i za ručne alate (sama reč alat, kalauz, burgija, turpija, igla, makaze, čekić, ekser...). Sa druge strane, nazivi za novije, mašinske alate po pravilu su iz nemačkog jezika (mašina, bormašina, bonsek, bandzeg, gvint, gvintborer, šraf, šrafciger, šaber, šlajferica, kleme...).

${ }^{8}$ Geneza novih izraza rimovanjem postoji i u srpskom ili hrvatskom slengu. Primer za to je uzrečica vamte-tamte, u značenju „ovamo, onamo”.
} 
mađarskog (cinkaroš, đilkoš, buđelar) i albanskog jezika (klopa) (Andrić, 1976; Imami, 2007). Svemu ovome treba dodati i veliki broj nezaobilaznih turcizama, ali i manje poznate istorijske primere kalajdžijskog slenga koji je sadržao leksiku aromunskog (cincarskog) (Sikimić, 1992: 275). No, svi navedeni jezici (uz delimičan izuzetak albanskog) temeljno su uticali na srpski ili hrvatski, posuđujući leksiku koja se koristi i u standardnom jeziku. Pozajmljenice iz romskog su pak po pravilu ograničene na manje-više etablirani žargon, ili pak na marginalizovani sleng.

Primer pozajmljenice koja je posebno relevantna u kriminalanom i zatvorskom slengu jeste izraz za improvizovano hladno oružje koje se pravi od komada armature, šipki od nameštaja, žileta itd. Takav predmet ne postoji van zatvoreničke populacije i nema nikakvu namenu, stoga nema ni naziv konvencionalnom govoru. Hipotetički, moguće bi bilo nazvati ovaj objekat prema njegovim vrlo upečatljivim atributima9. Ipak, u srpskom ili hrvatskom ovakav predmet se obično naziva šaber. Radi se dakle o pozajmljenici iz nemačkog jezika, koja je došla posredstvom žargona majstora (stolara i keramičara, pošto se u oba zanata koriste različiti alati zvani šaber, koji imaju zajedničku osobinu: oštar i krut špic). U engleskom jeziku pak, ovaj izraz dolazi iz romskog i glasi shiv ili izvorno chiv (Dalzell, 2009: 869) (moguć kognat sa savremenim romskim čhuri „nož”? (Krasnići, 2012: 88)).

\section{ANALIZA PRIMERA ROMIZAMA U ŽARGONU SRPSKOG ILI HRVATSKOG JEZIKA}

Lingvisti katkad grupišu reči prema formalnim kategorijama, takozvanim semantičkim grupama (delovi tela, životinje, hrana, radnje, društveni odnosi, lične osobine...) (Marković, 2021). Imajući u vidu cilj rada koji prevazilazi deskripciju leksike, ovde će osnovni kriterijum za grupisanje romizama u argou da bude njihova funkcija u govoru. Na taj način biće mnogo bolje pokazana društvena osnova ove jezičke pojave.

\subsection{Uvrede i psovke}

Glagol „psovati” dolazi od imenice „pas”, odnosno znači da se nekome obraća kao psu. Stoga se prvi primer sam nameće, budući da „džukela” nedvosmisleno potiče od romske reči za psa đukel (Krasnići, 2012: 147). Ipak, u jezičkoj praksi čak i kada se misli na stvarnog psa, izraz džukela se koristi u pejorativnom smislu (za ulične pse). Uobičajenije je da se ovaj izraz koristi za ljude kao generička uvreda. Sledeći primer, „dileja”, u značenju budala - nerazuman čovek ili čovek koji se čudno ponaša dolazi od romskog prideva dilo „lud” (Uhlik 1954: 13). Poznat je izraz „dilkarnica”: ludnica. Sledeći primer je nešto arhaičniji i izgubio je izvorno značenje, postavši vrlo uopštena uvreda. Verovatno svaki govornik ima neku svoju koncepciju šta tačno

\footnotetext{
9 Kao što je slučaj u ruskom jeziku gde se koristi izraz заточка (Троицкий, 200o), odnosno nešto „zatociljeno” (naoštreno/zašiljeno na tocilu).
} 
„kulov” znači, ali su sva ta značenja negativna. Ovde se možda može govoriti o (izvornoj) tajnosti argoa, ili o tome da se prvobitno značenje reči zaboravilo. Naime, khul na romskom znači „,izmet” (Krasnići, 2012: 206).

Posebnu grupu uvredljivih izraza čine oni koji su u vezi sa (odabranim) delovima tela. Tako u argou imamo izraze „mindža” u značenju vagina, od romskog minđ (Krasnići, 2012: 266); „bulja” u značenju zadnjica, od romske imenice bulja (množina od bul) (Krasnići, 2012: 72); „kara” u značenju penis i izvedeni glagol „karati”, od romske imenice kar (Krasnići, 2012: 198) i „kanditi” (smrdeti), od romskog glagola khnadav (Krasnići, 2012: 204).

\subsection{Izrazi o kriminalu ili zatvorskom životu}

Za razliku od prethodne grupe izraza, čija primena prevazilazi osuđeničke grupe i kriminalne subkulture, primeri koji slede su katkad manje poznati konvencionalnim govornicima srpskog ili hrvatskog, ili su pak zastareli i zaboravljeni. Rade Uhlik je tako sredinom prošlog veka zabeležio izraz „rain” za policajca od raj: gospodar ili sudija (Uhlik, 1954: 26) (kognat sa radža). Slično je i sa izrazom za (posudu za) vodu, „panija”, koja dolazi od reči za samu vodu, pani (Uhlik, 1954: 25) i „liluška” ili „iliška” sa značenjem dozvola, dokument, papir, lična isprava, od lil: list, papir (Uhlik, 1954: 21).

Leksika argoa koja je znatno više u upotrebi uključuje glagole „ćornuti” (ukrasti), ali i „ćorka” (pritvor ili zatvor), od čor: lopov (Krasnići, 2012: 90). Sa istim značenjem se koriste i izrazi „marnuti” i „marisati”, koje izvorno, kao što je već navedeno, na romskom znače udariti (marav) (Krasnići, 2012: 257). „Mangaš” u argou obično znači kriminalac, i baš kao i u navedenom engleskom primeru (mumper) u originalnom obliku znači prosjak (od romskog mangav, prositi) (Krasnići, 2012: 255). Još jedan pomalo zaboravljen izraz, „dandara”, udarac u glavu, dolazi preko romskog dand „zub” (Uhlik 1954: 12-13). „Marisati” može takođe da znači prebiti nekoga, a koristi se i izvedena imenica „mara” za batine.

Svakako relevantan izraz u ovoj grupi predstavljaju i „kidati” i „kidnuti” u smislu bežati (prvi ima homonim u srpskom jeziku, baš kao i raniji primer „karati”). Oba dolaze od kidav, što na romskom znači „uzeti” (Uhlik, 1954: 20). Sa bežanjem je tesno povezan osećaj straha i opreznosti, tako da se susreće i (istina vrlo redak i zastareo) izraz „daravela”, u smislu „panika” (Vučković, 2010: 129130), što dolazi iz romskog daravel: uplašiti, zastrašiti (Krasnići, 119). Sledeća dva glagola ne moraju nužno da budu povezani sa zatvorskom sredinom, ali iskazuju osnovne životne funkcije koje su tokom izdržavanja kazne po prirodi stvari u središtu pažnje: jedenje i spavanje. „Halisati” (jesti) dolazi od romskog xalo ili (po pravopisu koji koristi Alija Krasnići) hhalo (Krasnići, 2012: 167). Pored toga „hasati” (jesti) i „has” (jelo) su po svoj prilici romskog porekla (od

${ }^{10}$ Zanimljivo da je primetiti da ovde imamo i preuzimanje morfološkog elementa iz romskog jezika, za taj jezik tipičnog sufiksa -(v)ela, koji se javlja i u gradnji drugih izraza u srpskom slengu: brisavela i kuknjavela (Vućković, 2010: 131). 


\author{
Zbornik IKSI, 2-3/2021 - A. Kubiček \\ „Kriminalni argo (̌̌atrovački) i pozajmljenice iz romskog jezika”, (str. 77-89)
}

xas: jedeš). Takođe, „soviti” u smislu spavati je takođe pozajmljenica od romskog sovav (Krasnići, 2012: 382). Konačno, Rade Uhlik je zabeležio i još par primera koji su danas, čini se, izašli iz upotrebe, ali koji svedoče o istorijskom prisustvu još većeg broja reči: „đanisati”, u smislu „znati” od džanav (Uhlik, 1954: 15), zatim „pensati”, u značenju „reći”od phenav (Uhlik, 1954: 25).

\title{
5.3. Ostali izrazi
}

Na kraju, ostaje još nekoliko dobro poznatih izraza poreklom iz romskog koji nisu nužno vezani za kriminalni argo. Zanimljivo je da su dva naziva koje Romi koriste za nerome pozajmljena sa nešto izmenjenim značenjem. Tako pomalo arhaično „dasa”"1 (Uhlik, 1954: 13) ima pozitivno značenje u smislu zgodan, smeo ili lepo obučen čovek, odnosno momak. Drugi izraz, „gedža” (od romskog gadžo12) može da ima pejorativno značenje u smislu nečije jednostavnosti i prostodušnosti i vezuje se za seosko poreklo. Ipak, vremenom ${ }^{13}$ je ova reč postala odomaćena i prihvaćena kao afirmativan naziv za Srbijance i Šumadince.

Konačno, novac kao pojam koji je podjednako značajan i za zakonite i za nezakonite aktivnosti, takođe ima dobro poznat sinonim u argou. „Lova” dolazi od romskog love (Krasnići, 2012: 240). Osim toga, „lova”, sa „dasom” i „gedžom” jasno ukazuje na postojanje jednog trajnog društveno-prostornog konteksta u kom su romizmi ušli u srpski ili hrvatski jezik. Radi se o mestima za razmenu i trgovinu: pijacama, vašarima i sajmovima.

\section{ROMSKI U ŽARGONIMA DRUGIH EVROPSKIH JEZIKA (ENGLESKI, ŠPANSKI, RUMUNSKI, ČEŠKI I MAĐARSKI)}

Obim ovog rada prevazilazi mogućnosti detaljne uporedne analize srpskog ili hrvatskog sa drugim evropskim jezicima, ali je značajno ukazati na određene slične trendove. Primer engleskog jezika je već pomenut na više mesta. Kod njega takođe romizmi po pravilu pripadaju slengu i to često slengu koji koriste stariji govornici (Beal, Burbano-Elizondo, \& Llamas, 2012: 80-81). Ranije je u radu ukazano na zabeležene istorijske primere romizama u ovom jeziku, kao i na savremeni shiv (šaber), kome je moguđe dodati minge (vagina), pal (drugar, od phrala, brat) itd.

\footnotetext{
${ }^{11}$ Od romskog das, izraz za nerome hrišćane, koji može da se piše i velikim slovom ako se koristi kao ime određenog hrišćanskog naroda, najčešce za Srbe, Hrvate i Bugare.

${ }^{12}$ Koristi se za imenovanje neroma, ali takođe može da bude sinonim za većinsku etničku grupu koja živi na određenom prostoru (Srbe, Albance, Bugare, Rumune...). Na primer, na prostoru AP Kosova i Metohije Romi albanski jezik nazivaju gađikani ćhib (Krasnići, 2012: 152). Zanimljivo je da koren ove reči, gav znači „selo” (Krasnići, 2012: 155).

${ }^{13}$ A koristi se veoma dugo: u periodu od 1892. do 1895. godine izlazio je i humoristički časopis istog imena. Naime, Gedža je bio nadimak izdavača i urednika (bivšeg policajca i urednika ranije pominjanog i korišćenog Policijskog glasnika) Nauma Dimitrijevića, ali je kroz oštru političku satiru usmerenu prema političkoj eliti, dinastiji Obrenović i Austro-Ugarskoj Gedža postao sinonim za narodsku domišljatost i britak jezik (Rošulj, 1998).
} 


\author{
Zbornik IKSI, 2-3/2021 - A. Kubiček \\ „Kriminalni argo (šatrovački) i pozajmljenice iz romskog jezika”, (str. 77-89)
}

Pandan šatrovačkom u češkom jeziku je hantirka (hantýrka) ${ }^{14}$. Brojne reči preuzete iz romskog imaju jasne paralele u srpskom ili hrvatskom jeziku: bul (bulja), čokl (džukela), čórnout (ćornuti), chalovat (halisati); káro (kara); mindža (mindža, u češkom pogrdan naziv za ženu); kúlo (u značenju izmet, za razliku od kulov gde se bukvalno značenje gubi); lil (dozvola, dokument), raj (policajac); sovelit (soviti) (Fałowski, 2013).

Slična je situacija i u rumunskom, mađarskom i španskom jeziku, a u manjoj meri i nemačkom. Tako u španskom susrećemo bul i bullate (zadnjica) i minche (vagina), dok u mađarskom postoji izraz mindzsó. Kul(ov) ima pandane u mađarskom kula i španskom ful. Halisati (jesti) sreće se i u mađarskom halózik, rumunskom a hali i španskom jalar. Najstariju zabeleženu pozajmljenicu u srpskom, giljati (ići, hodati), prepoznajemo u mađarskom dzsal, španskom chalar, rumunskom geánă (žuriti). Glagol soviti ima pandan u španskom sobar. Lova je još jedna od reči koja je prihvaćena u slengovima više jezika: mađarskom lóvé i u rumunskom lovéle. U još većoj meri ovo važi za ćornuti: španski chorar ili chorelar; mađarski csórel, rumunskom cioran, ciordi, ciorti, ciordani pa čak i u nemačkom schornen. I gedža ima svoje paralele u češkom gádžo, španskom gachó i gachí (slično kao u srpskom, i u španskom ovaj izraz ima neutralno značenje za čoveka), rumunski gagiu (može da znači i svodnik ili ljubavnik), mađarskom gádzsó i nemačkom Gatscho (Krinková, 2015: 282-285).

Nije na odmet pomenuti da postoje i primeri evropskih jezika čiji slengovi nemaju upliv romskih reči, poput poljskog, čiji argo sa druge strane ima znatan uticaj leksike iz jidiša, kao što je slučaj i sa nemačkim u prvom redu, a zatim i sa češkim i mađarskim (Fałowski, 2013: 96).

\title{
ZAKLJUČAK
}

Primeri analizirani u radu nedvosmisleno pokazuju da se značajan deo romizama u srpskom ili hrvatskom argou, ali i u argoima drugih evropskih jezika, može svrstati u semantičku grupu koja se tiče kriminala. Bilo bi, međutim, pretenciozno doneti zaključak o nekakvoj inherentnoj vezi Roma i romskog jezika sa kriminalom, a posebno tvrditi da je romski rodno mesto „tajnog jezika lopova”. Kao i obično, ovakvo uverenje više svedoči o trajnim društvenim strukturama koje oblikuju mišljenje onih koji takva uverenja neguju i šire. Većina leksike slenga i argoa potiče iz matičnog jezika, srpskog ili hrvatskog. Takođe, romizmi nisu jedine pozajmljenice $\mathrm{u}$ argou, već njegov rečnik deli poreklo iz najrazličitijih jezika, u zavisnosti od istorijskih okolnosti (danas se najviše reči pozajmljuje iz engleskog).

\footnotetext{
${ }^{14}$ I u češkom jeziku je ovaj fenomen odavno zabeležen u knjizi Karela Juda Tajná řeč (hantýrka) zloděju a šibalů (Tajni govor (argo) lopova i lupeža) iz 1902. godine i Františeka Bredlera iz 1914, Slouník české hantýrky (tajné řeči zlodějské) (Rečnik češkog argoa (tajnog govora lopova)). Istraživanje ovih knjiga pokazala su prisustvo oko 200 reči romskog porekla ((Hugo, 2009: 19, 26).
} 
Realističnije je zaključiti da je društveno-prostorni kontekst u kome se komunikacija između Roma i većinskog stanovništva - bilo da se radi o Srbima, Hrvatima, Mađarima, Rumunima, Cesima ili Španacima - presudno uticala na selekciju pozajmljenica. Taj prostor bi se najšire mogao odrediti onako kako ga i sami govornici imenuju, kao „ulica”: fluidni prostor susreta i odlaska, mesto razmene roba i usluga, ali i krađa, nasilja i prevara. Ta „ulica” kao rodno mesto „uličarskog” slenga spaja i zatvor i pijacu, kao druga dva društveno-prostorna konteksta geneze nestandardnih varijeteta govora. Ovaj milje nije dakle isključivo kriminalan, zbog čega se i govor nastao u njemu ne može svesti na kriminalne subkulture. Naprotiv, upravo konspirativni izrazi nestaju iz jezičke prakse, dok oni romizmi koji su prihvaćeni u širim govornim zajednicama opstaju vekovima, doprinoseći autentičnosti komunikacije i izražajnom bogatsvu.

\section{LITERATURA:}

(1) Andrić, D. (1976). Rečnik žargona, Beograd: BIGZ.

(2) Bakker, P. (2002) An Early Vocabulary of British Romani (1616): A Linguistic Analysis. Romany Studies, 12(2), 75-101. http://dx.doi.org/10.3828/rs.2002.4

(3) Batrićević, A \& Kubiček, A (2020). The role of tattoos in prison community. Journal of Criminology and Criminal Law, 58(3), 7-22. https://doi.org/10.47152/rkkp.58.3.1

(4) Beal, C. J., Burbano-Elizondo, L. \& Llamas, C. (2012). Urban North-Eastern English: Tyneside to Teesside. Edinburgh: Edinburgh University Press.

(5) Bugarski, R. (2005). Jezik i kultura. Beograd: Biblioteka XX vek.

(6) Ćosić, P. (2004). Pravila žargonske metateze. Jezik danas, VIII(19-20), 14-17.

(7) Coleman, J (2012). The Life of Slang. Oxford: Oxford University Press.

(8) Dalzell, T. (2009). The Routledge Dictionary of Modern American Slang and Unconventional English. Routledge.

(9) Đurić, R. (2021). Romologija. Beograd: Tim za socijalno uključivanje i smanjenje siromaštva Vlade Republike Srbije.

(10) Eble, C. (1996). Slang and Sociability. Chapel Hill: Univeristy of North Carolina Press.

(11) Fałowski, P. (2013). Words of Romani Origin in the Czech and Croatian Languages. Studia Linguistica Universitatis Iagellonicae Cracoviensis, 13o(2), 95-115. https://doi.org/10.4467/20834624SL.13.006.1137

(12) Filipović, J. (2009). Moć reči. Beograd: Zadužbina Andrejević.

(13) Hugo, J. (2009). Slovník nespisovné češtiny. Praha: Maxdorf.

(14) Ilijić, Lj. (2014). Osuđeni i deprivacije: uticaj karakteristika ličnosti na intenzitet doživljavanja zatvorskih deprivacija. Beograd: Institut za kriminološka i sociološka istraživanja.

(15) Kinney, A. F. (1990). Rogues, Vagabonds \& Sturdy Beggars: A New Gallery of Tudor and Early Stuart Rogue Literature Exposing the Lives, Times, and Cozening Tricks of the Elizabethan Underworld. Amherst: University of Massachusetts Press.

(16) Krasnići, A. (2012). Angluno rromano-srbikano-srbikano-rromano alavari; Prvi romsko-srpski-srpsko-romski rečnik. Subotica: Rromane pustika - Romske knjige.

(17) Krinková, Z (2015). The Comparison of Loanwords from Romani to Be Found in NonStandard Hungarian, Spanish, Czech and Romanian. Argumentum, 11, 274-291. 
(18) Kubiček, A. (2018). Roma nation: escaping pariah people's stigma? In G. Pudar Draško, A. Pavić, \& E. Meka (Eds.). Politics of Enmity. Belgrade, Serbia: Institute for Philosophy and Social Theory.

(19) Leburić, A. \& Šuljug, Z. (2008). Metodološki aspekti istraživanja jezika kao društvenog fenomena. Zbornik radova Filozofskog fakulteta u Splitu, 1, 131-146.

(20) Lombroso, C. (1911a). Criminal man. New York: G. P. Putnam’s Sons.

(21) Lombroso, C. (1911b). Crime, its Causes and Remedies. Boston: Little Brown and co.

(22) Marković, I. (2021). O hrvatskome šatrovačkome jeziku 1912. Filologija, 76, 145174. https://dx.doi.org/10.21857/ypn4oc1vq9

(23) Nikolić, Z. (2009). Savremena penologija: Studija kazni i kažnjavanja. Beograd: IKSI.

(24) Imami, P. (2007). Beogradski frajerski rečnik. Beograd: NNK.

(25) Partridge, E. (2006). The Routledge Dictionary of Historical Slang. Routledge. http://dx.doi.org/10.4324/9780203380963

(26) Petrović, T. (2015). Srbija i njen Jug: „južnjački dijalekti” između jezika, kulture i politike. Beograd: Fabrika knjiga.

(27) Radovanović, M. (1979). Sociolingvistika. Beograd: BIGZ.

(28) Rošulj, Ž. (1998). Čas opisa časopisa II: Gedža. Beograd: Institut za književnost i umetnost.

(29) Schrammel, B \& Halwachs, D. W. (2005). General and Applied Romani Linguistics - Proceeding from the 6th International Conference on Romani Linguistics. Lincom: Munich. ISBN 3-89586-741-1

(30) Sikimić, B. (1992). Balkan secret languages vs. modern slang: Romanian contribution. Revue Études Sud-Est Europeennes, XXX(3-4), 275-289.

(31) Троицкий, А. Б. (2000). Удар из прошлого. Москва: Вагриус.

(32) Uhlik, R. (1954). Ciganizmi u šatrovačkom argou i u sličnim govorima. Glasnik Zemaljskog muzeja u Sarajevu, 9, 5-31.

(33) Vučković, M. (2010). Serbian Prison Jargon: Daravela “An Alarmist”. Балканско езикознание, XLIX(1-2), 129-134.

\section{Izvori:}

(34) Policijski glasnik (1897) godina I, broj 1, Beograd: Državna štampa Kraljevine Srbije. 


\section{CRIMINAL ARGOT ( $\breve{S} A T R O V A \check{C} K I)$ AND ROMANI LOANWORDS}

Starting from the assumption that the lexicon of one language - standard or some other form of it - testifies to the basic social processes, the article explores the origin and development of the so-called "šatrovački" speech. To achieve this goal, it is necessary to introduce first a conceptual difference between related phenomena: jargon, slang, and argot (šatrovački, cant, or cryptolect). Although these language varieties are often considered spontaneous and ephemeral, the paper will show that they are often permanent linguistic phenomena that characterize criminal and marginalized subcultures. A special focus will be on the emergence of new vocabulary through borrowings from the Romani language. The article explores the genesis and function of these speech practices, highlighting the similarities that exist in several European languages and that testify to similar social processes. Finally, the paper also aims to point out the porosity of symbolic boundaries between marginalized and established ways of expression through their interpenetration.

KEYWORDS: šatrovački / slang / jargon / Romani language / loanwords. 